\title{
ADAPTABILIDADE E ESTABILIDADE FENOTÍPICA EM GENÓTIPOS DE FEIJÃO DE COR (Phaseolus vulgaris L.) EM TRÊS AMBIENTES DISTINTOS
}

\author{
ADAPTABILITY AND FENOTYPIC STABILITY OF COLLOR BEAN GENOTYPES \\ (Phaseolus vulgaris L.) IN THREE DIFFERENT ENVIRONMENTS
}

\author{
Jefferson Luís Meirelles Coimbra ${ }^{1}$ Fernando Irajá Felix de Carvalho \\ Silmar Hemp ${ }^{3}$ Simone Alves Silva ${ }^{4}$
}

\section{RESUMO}

\begin{abstract}
No biênio 1996/97 foram testados, em três ambientes, vinte e um genótipos de feijão de cor, com o objetivo de identificar e avaliar os parâmetros de adaptabilidade e estabilidade fenotípica para a produtividade de grãos. Foi utilizado o delineamento experimental, blocos casualizados, com três repetições por tratamento. Os genótipos revelaram diferenças altamente significativas entre si, em todos os ambientes avaliados. $\mathrm{Na}$ análise de variância conjunta, os efeitos das causas de variação foram altamente significativos, evidenciando diferenças entre genótipos, ambientes e a existência de um comportamento diferenciado entre os genótipos frente às variações de ambientes. $O$ rendimento médio de grãos variou de $1321 \mathrm{~kg} / \mathrm{ha}$ a $801 \mathrm{~kg} / \mathrm{ha}$, com média geral de $1081 \mathrm{~kg} / \mathrm{ha}$. A maioria dos genótipos demonstraram alta estabilidade fenotípica, merecendo destaque os genótipos LP 93-15, LP 93,2, LP 93-38 e Rudá, os quais evidenciaram rendimento médio superior à média geral dos ensaios, adaptabilidade geral e comportamento previsível em todos os ambientes estudados. Entre os genótipos com rendimento de grãos abaixo da média geral podem ser destacados os genótipos AN 9022180 , LM 93204319, LR 91155315, PF 9029975, PF 9029984 e TB 94 05, com adaptabilidade geral e alta estabilidade fenotípica nos ambientes avaliados.
\end{abstract}

Palavras-chave: Phaseolus vulgaris L., estabilidade fenotípica.

\section{SUMMARY}

In the biennium 1996/97, twenty-one genotypes of colored bean were evaluated, in three environments, to identify and estimate adaptability parameters and phenotypic stability for grains yield. The experimental design was randomized blocks with three replications per treatment. The genotypes revealed highly significant differences among them, in all evaluated environments. In the analysis of joint variance, the genotype effects, environment and the interaction genotype $x$ environments were highly significant, showing differences among genotypes $x$ environment, and the existence of a differentiated behavior among genotypes according to enviromental variation. Average grain yields varied from $1321 \mathrm{~kg}^{-\mathrm{ha}^{-1}}$ to $801 \mathrm{~kg}^{\mathrm{h}} \mathrm{ha} \mathrm{H}^{-1}$, with on overall average of $1081 \mathrm{~kg}^{-h \mathrm{~h}^{-1}}$. Most of the genotypes evidenced high phenotypic stability, specially LP 93-15, LP 93,2, LP 93-38 and Rudá, which showed superior average yield compared to the overall yield average, general adaptability and predicted behavior in all the studied enviroments. Among the genotypes with grain yield below the overall average AN 9022180, LM 93204319, LR 91155315, PF 9029975, PF 9029984 and TB 9405 presented general adaptability and high phenotipic stability in the environments evaluated.

Key words: Phaseolus vulgaris L, phenotypic stability.

\section{INTRODUÇÃO}

O feijão (Phaseolus vulgaris L.) está entre as culturas de estação quente de maior importância para os estados do sul do Brasil, provavelmente pela sua participação na formação da renda do agricultor e, principalmente, pela sua contribuição na alimentação humana, onde participa como um dos principais componentes da dieta humana. A cultura do feijoeiro é difundida por todo o Brasil (RAMALHO et al., 1993). Para os autores

${ }^{1}$ Engenheiro Agrônomo, aluno do Curso de Pós-graduação em Agronomia da Universidade Federal de Pelotas (UFPel). Bolsista da CAPES.

${ }^{2}$ Engenheiro Agrônomo, PhD., Professor da Faculdade de Agronomia, UFPel. Pesquisador do CNPq. CP 354, 96001-970, Capão do Leão, RS. E-mail: jlmcpos@pos ufpel.tche.br.

${ }^{3}$ Engenheiro Agrônomo, Mestre, Pesquisador da EPAGRI, CTA do Oeste Catarinense.

${ }^{4}$ Engenheiro Agrônomo, aluno do Curso de Pós-graduação em Agronomia, UFPel. 
BISOGNIN et al. (1997), a cultura do feijão tem sido semeada em Santa Catarina em duas épocas, sendo denominadas de safra (setembro a novembro) e safrinha (janeiro a fevereiro), respectivamente.

$O$ componente da interação genótipo $x$ ambiente, apesar de ser de grande importância para o melhoramento genético, não proporciona informações pormenorizadas sobre o comportamento de cada genótipo frente às variações de ambiente (CRUZ \& REGAZZI 1997). Desta forma, o estudo de parâmetros que estimam a adaptabilidade e estabilidade fenotípica servem para caracterizar um grupo de genótipos quanto à sua resposta relativa às variações de ambiente. Segundo JOBIM (1990) e BILBRO \& RAY (1976), o modelo de análise proposto por EBERHART \& RUSSEL (1966) é informativo, pois utiliza três parâmetros, adaptabilidade, estabilidade e o rendimento médio de grãos, proporcionando um benefício significativo na avaliação e caracterização de genótipos em programas de melhoramento. De acordo com este modelo, o parâmetro de adaptabilidade indica linearmente quanto o comportamento de um genótipo responde às melhorias das condições de ambiente. Por outro lado, o parâmetro que estima a estabilidade fenotípica possibilita prever o desempenho do genótipo de um modo previsível. SOARES et al. (1995) comentam as dificuldades na obtenção de genótipos com estabilidade para uma grande faixa de ambientes distintos.

Segundo ALLARD \& BRADSHAW (1964), existem duas condições de ambiente que contribuem para a interação genótipo x ambiente. A primeira é denominada previsível e inclue as variações de ambiente que ocorrem de local para local, dentro da área de distribuição da cultura. Dentro desta condição de ambiente, estão características como: clima, solo e técnicas agronômicas, etc. A segunda condição compreende as variações imprevisíveis, como frequiência e distribuição de chuvas, temperatura do ar e do solo, ocorrência de geadas, entre outras.

Considerando estes aspectos, o presente trabalho teve por objetivos estimar e avaliar os parâmetros de adaptabilidade e estabilidade fenotípica na produção de grãos por unidade de área de vinte e um genótipos de feijão de cor, quando submetidos a condições de ambiente que contribuem para o componente da interação genótipo $\mathrm{x}$ ambiente.

\section{MATERIAL E MÉTODOS}

Foram utilizados os dados de rendimento médio de grãos de 21 genótipos de feijão de cor comuns em três Ensaios Sulbrasileiro de Feijão (ESB), realizados no município de Chapecó/SC, no biênio 1996/97.
O preparo do solo foi realizado segundo recomendações técnicas (WILDNER, 1992). As adubações seguiram determinações descritas pelos autores BALDISSERA \& SCHERER (1992). O controle de plantas invasoras foi efetuado com aplicação de $2 \mathrm{~kg} / \mathrm{ha}$ de Metachlor, sendo posteriormente realizada capina manual para eliminação de possíveis invasoras remanescentes, de acordo com a metodologia descrita por GUIMARÃES (1992). Para o controle de pragas foi utilizado o inseticida Methamidophos (Tamaron BR) nas doses de 0,5 a 1,0l/ha do produto comercial. Estes controles foram realizados sempre que necessários.

Os genótipos de feijão de cor incluídos neste ensaio constituíram de 18 linhagens e três cultivares utilizados como padrão (tabela 1). O delineamento experimental empregado foi o de blocos ao acaso, com três repetições e em três épocas de semeadura. Cada unidade experimental foi composta por duas fileiras de $5 \mathrm{~m}$ de comprimento com 10 plantas/m linear ou 200.000 plantas/ha. O espaçamento foi de $0,5 \mathrm{~m}$ entre fileiras e $0,2 \mathrm{~m}$ entre covas dentro das fileiras. A área útil formada de duas fileiras compreendeu $4 \mathrm{~m}^{2}$. As três épocas de semeadura, no ano agrícola de 1996/97, receberam manejo semelhante em todos os experimentos avaliados.

As semeaduras foram realizadas no ambiente $A_{1}$ em 08/02/96, no ambiente $A_{2}$ em 04/10/1996 e no ambiente $A_{3}$ em 05/02/97. A época de semeadura para o ambiente $A_{2}$, de acordo com o Zoneamento Agroclimático de SC, ocorreu dentro do período preferencial para a cultura, enquanto que para os ambientes $A_{1}$ e $A_{3}$, coincidiu com o cultivo de safrinha no oeste catarinense. A variável avaliada foi o rendimento de grãos a 13\% de umidade; as análises foram realizadas de forma a levar em consideração as três condições de ambiente, que correspondem às épocas de semeadura.

Para os testes de hipótese sobre os efeitos do modelo foi usado o quadrado médio do erro (QME). As médias dos genótipos foram comparadas pelo teste de dms de Fisher $(\alpha=0,05)$. Após a análise conjunta para todos os ambientes, foi determinado os parâmetros de adaptabilidade e estabilidade, seguindo a metodologia proposta por EBERHART \& RUSSEL (1966), conforme segue abaixo:

$$
\mathbf{Y}_{\mathrm{ij}}=\mu_{\mathrm{i}}+\beta_{\mathrm{i}} \mathbf{I}_{\mathbf{j}}+\mathbf{S}_{\mathrm{di}}^{2}
$$

onde: $\mathrm{Y}_{\mathrm{ij}}=$ média do cultivar $\mathrm{i}$ no ambiente $\mathrm{j} ; \mu_{\mathrm{i}}=$ média do cultivar $\mathrm{i}$ em todos os ambientes; $\beta_{\mathrm{i}}=$ coeficiente de regressão; $I_{j}=$ índice de ambiente; $S^{2}{ }_{d i}$ $=$ desvios da regressão, mais o erro experimental contido em $\mathrm{Y}_{\mathrm{ij}}$. 
Tabela 1 - Produtividade média de grãos (kg/ha) de vinte genótipos de feijão do tipo carioca, avaliados em dois ambientes: média geral de locais (Y.j) e de genótipos ( $\mathrm{Y}_{\mathrm{i} .}$ ); variâncias residuais das médias (QMR) e o dos genótipos (QMT) e o coeficiente de variação em percentagem $(\mathrm{CV})$

\begin{tabular}{|c|c|c|c|c|c|}
\hline \multirow[b]{2}{*}{ Genótipos } & \multicolumn{3}{|c|}{ Ambientes } & \multirow[b]{2}{*}{ Total } & \multirow[b]{2}{*}{$\mathrm{Y}_{\mathrm{i}}$} \\
\hline & 1 & 2 & 3 & & \\
\hline AN 9022180 & 708 & 637 & 1094 & 2439 & 813 \\
\hline Carioca $^{\mathrm{P}}$ & 973 & 1260 & 1339 & 3572 & 1191 \\
\hline Carioca80 $\mathrm{SH}^{\mathrm{P}}$ & 940 & 1133 & 1625 & 3697 & 1232 \\
\hline FT 206 & 863 & 1085 & 1357 & 3306 & 1102 \\
\hline IAPAR $31^{\mathrm{P}}$ & 925 & 1021 & 1539 & 3485 & 1162 \\
\hline LM 93204319 & 891 & 763 & 1259 & 2913 & 971 \\
\hline LP 93-15 & 1298 & 1024 & 1429 & 3751 & 1250 \\
\hline LP 93-16 & 1654 & 616 & 1314 & 3584 & 1194 \\
\hline LP 93-18 & 1086 & 558 & 1385 & 3029 & 1010 \\
\hline LP 93-2 & 1076 & 1117 & 1361 & 3555 & 1185 \\
\hline LP 93-28 & 1603 & 843 & 1517 & 3963 & 1321 \\
\hline LP 93-29 & 1577 & 896 & 1407 & 3879 & 1293 \\
\hline LP 93-33 & 1299 & 665 & 1256 & 3220 & 1073 \\
\hline LP 93-38 & 931 & 848 & 1252 & 3030 & 1010 \\
\hline LP 93-81 & 964 & 1139 & 1121 & 3223 & 1074 \\
\hline LR 9115315 & 921 & 559 & 1200 & 2681 & 894 \\
\hline Pérola & 1526 & 907 & 1250 & 3684 & 1228 \\
\hline PF 9029975 & 865 & 755 & 1030 & 2650 & 883 \\
\hline PF 9029984 & 858 & 777 & 1049 & 2684 & 895 \\
\hline Rudá & 1135 & 912 & 1331 & 3379 & 1126 \\
\hline ТВ 94-05 & 809 & 648 & 945 & 2403 & 801 \\
\hline Total & 68.714 & 54.487 & 81.185 & 204.386 & \\
\hline$Y_{. j}$ & $1.091 \mathrm{M}$ & $865 \mathrm{I}$ & $1.289 \mathrm{~S}$ & & $1.081,41$ \\
\hline $\mathrm{CV}$ & 10,89 & 19,96 & 10,80 & & \\
\hline QMT & $247772^{* *}$ & $133405^{* *}$ & $19375^{* *}$ & & \\
\hline QMR & $14.115,00$ & $29.810,55$ & $19.375,91$ & & $21.100,53$ \\
\hline
\end{tabular}

${ }^{* * /}$ significativo ao nível de $1 \%$ de probabilidade pelo teste de $\mathrm{F}$.

$\mathrm{S}, \mathrm{M}$ e I indicam genótipo superior, médio e inferior, respectivamente, a $5 \%$ de probabilidade, pelo teste do dms.

P genótipos padrão.

Foi estimado, também, o desvio da regressão do cultivar i no ambiente $\mathrm{j}\left(\mathrm{S}_{\text {dij }}^{2}\right)$ e coeficiente de determinação $\left(R^{2}\right)$, segundo STEEL \& TORRIE (1960). Os parâmetros de adaptabilidade e estabilidade fenotípica, de acordo com o modelo proposto por EBERHART \& RUSSEL (1966), foram estimados com o auxílio do programa computacional GENES (CRUZ, 1997).

\section{RESULTADOS E DISCUSSÃO}

A produtividade média de grãos e os valores do quadrado médio dos tratamentos da estatística
F, resultantes das análises de variância de cada ensaio, estão inseridos na tabela 1. A terceira época revelou a maior produtividade média de grãos $(1289 \mathrm{~kg} / \mathrm{ha})$, e a segunda, a menor produtividade média de grãos $(865 \mathrm{~kg} / \mathrm{ha})$. Tal fato, revela a existência de uma ampla variação entre os ambientes avaliados. O procedimento de análise de variância padrão prevê estimativas da interação genótipo $\mathrm{x}$ ambiente. Segundo SMITH et al. (1967), este procedimento revela uma informação relativamente pequena para a estabilidade fenotípica de genótipos nos diferentes ambientes. Desta forma, as diferenças altamente significativas encontradas entre os ambi- 
entes confirmaram as divergências ecológicas necessárias para o estudo dos parâmetros de adaptabilidade e estabilidade fenotípica. Segundo ALLARD \& BRADSHAW (1964), ambientes distintos são imprescindíveis em um programa de melhoramento para a detecção e seleção de genótipos estáveis e adaptados. Pode ser observado ainda na tabela 1, que os efeitos de genótipos foram altamente significativos, em nível de significância de $1 \%$ de probabilidade pelo teste de F, em todos os ambientes. Os coeficientes de variação oscilaram de 10 a $20 \%$, conferindo boa precisão às estimativas preditas nestes três ensaios.

Os resultados da análise conjunta de variância para o rendimento de grãos dos genótipos testados nos três ambientes (tabela 2) evidenciaram que os efeitos isolados dos genótipos em ambientes apresentaram variações altamente significativas. A magnitude da variância dos quadrados médios revela que as diferenças entre ambientes foram maiores. Os valores estimados do quadrado médio da interação genótipo $\mathrm{x}$ ambiente mostraram variações altamente significativas. Fato este, que demonstra a existência de diferenças entre genótipos quanto a suas respostas frente às variações de ambiente, concordando com ALLARD \& BRADSHAW (1964), que comentam a importância das diferenças entre ambientes nos programas de melhoramento. Tal fato é um indicativo de viabilidade de detecção de genótipos estáveis e adaptados.

Ainda na tabela 2, estão inseridos os resultados da análise de variância para investigar a

Tabela 2 - Análise conjunta da variância de 21 genótipos de feijão de grãos tipo carioca para produtividade de grãos em $\mathrm{kg} / \mathrm{ha}$, em três ambientes do município de Chapecó/SC, no biênio 1996/97

\begin{tabular}{lcr}
\hline \multicolumn{1}{c}{ Fonte de variação } & GL & \multicolumn{1}{c}{ Q.M. } \\
& & \\
& & \\
Genótipos (G) & 20 & $225.928,37^{* *}$ \\
Ambientes (A) & 2 & $2.832 .586,72^{* *}$ \\
Interação (GxA) & 40 & $123.105,45^{* *}$ \\
Ambiente Linear (AL) & 1 & $5.665 .220,00^{* *}$ \\
Genótipo x Ambiente & 20 & $672.85,95^{* *}$ \\
Linear & & $170.400,78^{* *}$ \\
Desvio Combinado & 21 & 21100,53 \\
Resíduo & 120 & \\
& & \\
**/ significativo em nível de 5\% de probabilidade, pelo teste de &
\end{tabular}

estabilidade com a decomposição da variância de ambiente dentro dos genótipos em efeitos lineares e não lineares. Assim sendo, o efeito do ambiente pode ser desmembrado em dois componentes, um linear $\left(b_{i}\right)$ e outro não linear $\left(S^{2}{ }_{\mathrm{di}}\right)($ EBERHART \& RUSSEL, 1966). Esta tabela mostra que a magnitude da variância dos efeitos lineares foi significativamente maior que a dos desvios combinados da regressão. A significância da interação genótipo $\mathrm{x}$ ambiente (linear) revelou a existência de diferença entre os coeficientes de regressão linear dos genótipos avaliados, possibilitando, assim, através do método proposto, identificar genótipos com maior adaptabilidade, ou seja, com capacidade de responder à melhoria do ambiente, e estabilidade de comportamento da constituição genética avaliada. O parâmetro de estabilidade fenotípica $\left(\mathrm{S}_{\mathrm{d}}^{2}\right)$, para os autores GAMA \& HALLAUER (1980), é muito importante quando a soma de quadrados da interação genótipos $\mathrm{x}$ ambiente (linear) é uma pequena fração do total da interação genótipo $\mathrm{x}$ ambiente.

As produtividades médias de grãos, os coeficientes de regressão, as variâncias dos desvios de regressão e os coeficientes de determinação estão na tabela 3. A produtividade média de grãos foi dividida em três grupos: superior (S), médio $(\mathrm{M})$ e inferior (I), sendo que dentro de cada subgrupo estão inseridos sete genótipos. A produtividade média de grãos variou de $1321 \mathrm{~kg} / \mathrm{ha}$ (LP 93-28) a $801 \mathrm{~kg} / \mathrm{ha}$ (TB 94-05), com média geral de $1081 \mathrm{~kg} / \mathrm{ha}$, evidenciando um bom desempenho produtivo dos genótipos nos ambientes estudados, principalmente dos sete genótipos pertencentes ao grupo dos superiores, sendo que todos os genótipos ficaram acima da média geral. A média de produção dos três cultivares usados como padrão (Carioca, Carioca $80 \mathrm{SH}$ e IAPAR 31) no ensaio superaram a média geral do experimento. A análise do rendimento de grãos das linhagens apontou que, nos grupos médio e superior em produção, estão contidos, respectivamente, seis e cinco linhagens.

Os coeficientes de regressão linear variaram de 0,05 (LP 93-81) a 1,96 (LP 93-18), não diferindo da unidade $(\mathrm{b}=1)$ pelo teste $\mathbf{t}$, ao nível de $5 \%$ de probabilidade, para os genótipos (AN 9022180, Carioca 80SH, FT 206, IAPAR 31, entre outros), sendo que $76 \%$ do número total dos genótipos avaliados evidenciaram ampla adaptabilidade aos ambientes estudados. Por outro lado, três genótipos (LP 93-16, LP 93-18 e LP 93-28) foram significativamente superiores à unidade $(\mathrm{b}>1)$, indicando a tendência desses genótipos para adaptabilidade em 
ambientes favoráveis, e dois genótipos (Carioca e LP 93-81) inferiores à unidade $(\mathrm{b}<1)$, atribuindo aos mesmos maior ajuste a ambientes desfavoráveis.

O genótipo LP 93-18 é o tratamento genético que mais acusa um aumento médio no rendimento de grãos $(b=1,96)$, ou seja, incremento de $96 \mathrm{~kg} / \mathrm{ha}$ para cada $100 \mathrm{~kg} / \mathrm{ha}$ devido à melhoria das condições de ambiente entre os ensaios investigados. Por outro lado, para o genótipo LP 93-81, provavelmente não haveria incremento na produtividade de grãos com melhoria das condições de ambiente. Neste caso, este genótipo é o menos responsivo dentre os 21 genótipos avaliados. Todos os genótipos, com exceção do Carioca, Carioca 80SH, FT 206, IAPAR 31, LP 93-16, LP 93-28, LP 93-29, LP 93-33 e Pérola, apresentaram desvios da regressão linear significativos pelo teste de F, em nível de $5 \%$ de probabilidade, evidenciando comportamento altamente imprevisível em todos os ambiente, ou seja, constituição genética de baixa estabilidade (tabela 3).

Considerando estes resultados, a grande maioria dos genótipos mostrou alta previsibilidade para as condições de ambiente do Oeste Catarinense, merecendo destaque os genótipos LP 93-15, LP 93-2, LP 93-38 e RUDÁ, os quais evidenciaram produtividade média de grãos superior à média geral, alta adaptação e ampla estabilidade nos ambientes avaliados. ROWE \& ANDREW (1964) sugeriram que as diferenças de estabilidade fenotípica sobre genótipos estão associadas com diferenças genéticas capazes de explorar favoravelmente o ambiente. Além disso, estes genótipos revelaram altos coeficientes de determinação (tabela 3), indicando que grande parte de suas variações totais são explicadas pelo modelo adotado. As regressões lineares do rendimento de grão desses genótipos, em função do índice de ambiente, comparadas à média geral são apresentadas na figura $1 \mathrm{~A}, \mathrm{~B}, \mathrm{C}$ e D. O genótipo LP 93-18, apesar de apresentar rendimento acima da média geral e comportamento previsível em todos os ambientes, evidenciou a desvantagem de adaptação a ambientes favoráveis (figura $1 \mathrm{E}$ ). Os genótipos Carioca 80 SH, FT 206, IAPAR 31, LP 93-29, LP 93-33 e Pérola, também com rendimento acima da média geral, revelaram alta adaptação, porém com baixa estabilidade ou previsibilidade de comportamento. O genótipo Carioca, além de apresentar rendimento acima da média e baixa estabilidade, apontou como vantagem a adaptabilidade a ambientes desfavoráveis (figura $1 \mathrm{~F}$ ). Os genótipos AN 9022180, LM 93204319, LR 9115315, PF 9029975, PF 9029984 e TB 9405, apesar de suas produtividades abaixo da média geral dos ensaios, apresentaram em sua maioria bom potencial para produtividade de grãos, ampla adaptação e alta previsibilidade nos ambientes estudados (figura $2 \mathrm{~A}, \mathrm{~B}$, C, D, E e F). 

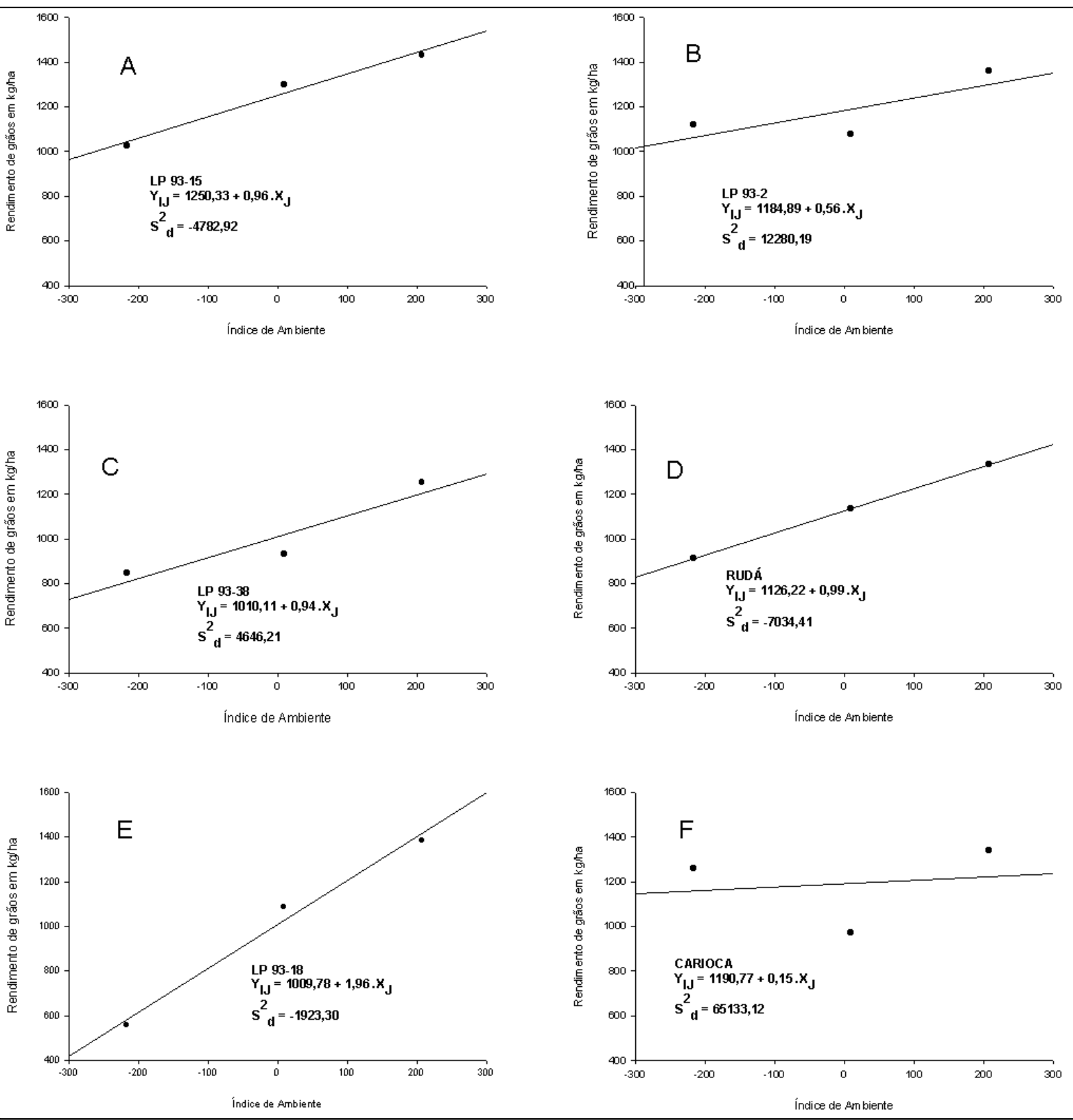

Figura 1 - Regressões lineares para a produtividade de grãos dos genótipos LP 93-15, LP 93-38, LP 93-18 e LP 93-2 com produção de grãos acima da média geral dos três ensaios, adaptabilidade geral e alta estabilidade fenotípica. Os gráficos Rudá e Carioca referente aos genótipos com rendimento médio acima da média geral, alta previsibilidade e adaptação a ambientes favoráveis e o gráfico $\mathrm{F}$, apesar de apresentar rendimentomédo acima da média geral, baixa estabilidade fenotípica e adaptação a ambientes desfavoráveis, respectivamente.

\section{CONCLUSÃO}

As diferenças de ambientes estudados influenciaram no comportamento dos genótipos, tanto na adaptação quanto na previsibilidade fenotípica. Dentre os genótipos estudados, os LP 93-15, LP 932, LP 93-38 e RUDÁ associaram um bom potencial de produtividade, alta capacidade de adaptação e estabilidade fenotípica. Entre os genótipos com rendimento de grãos abaixo da média geral, sobressaíram AN 9022180, LM 93204319, LR 91155315, PF 9029975, PF 9029984 e TB 94-05, com adaptabilidade geral e alta estabilidade fenotípica nos ambientes avaliados.

Ciência Rural, v. 29, n. 3, 1999. 

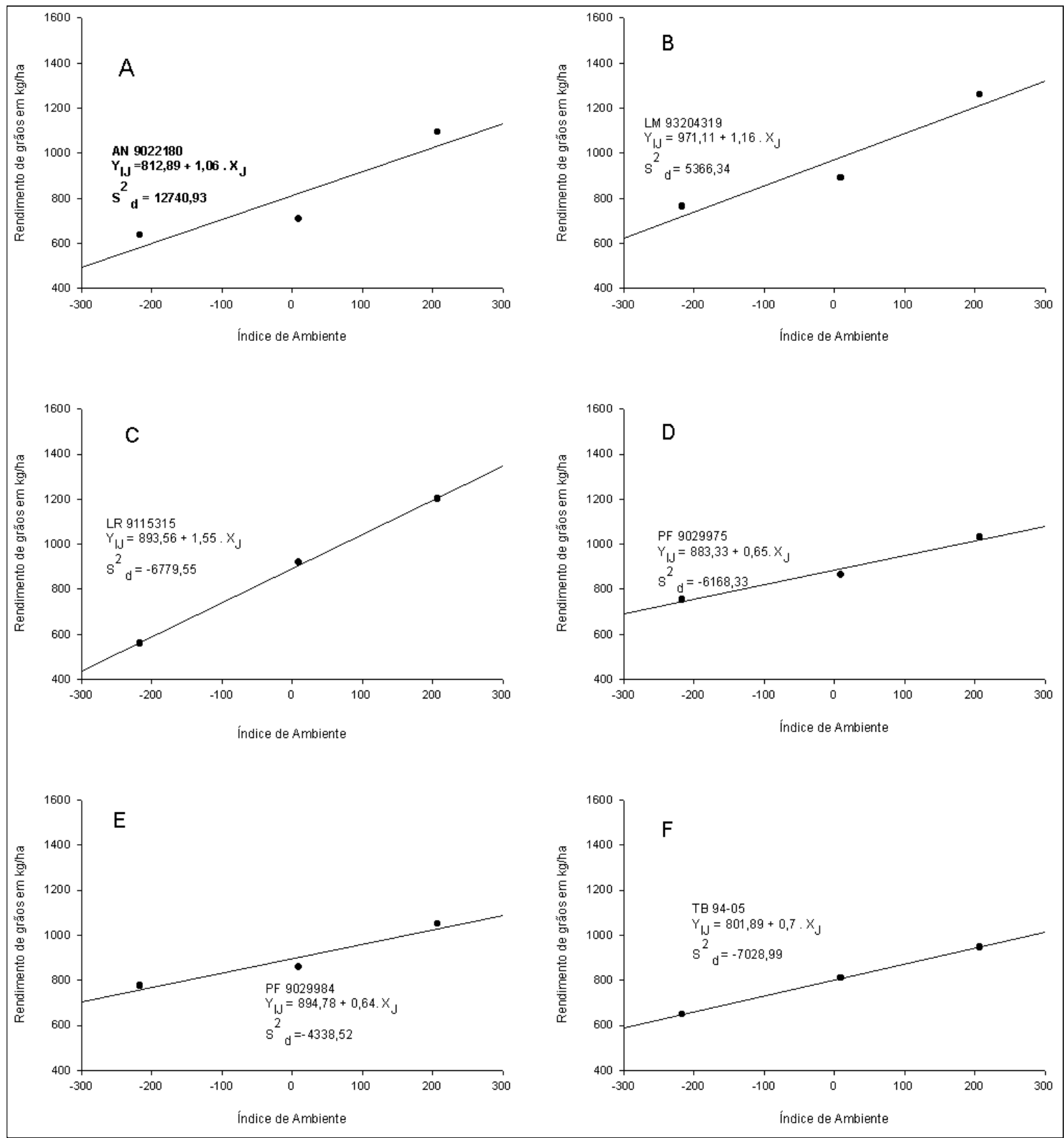

Figura 2 - Regressões lineares para a produtividade de grãos dos genótipos AN 9022180, LR 9115315, PF 9029984, LM 93204319, PF 9029975 e TB 94-05 com produção de grãos abaixo da média geral dos três ensaios, adaptabilidade geral e alta estabilidade fenotípica.

\section{REFERÊNCIAS BIBLIOGRÁFICAS}

ALLARD, R.W., BRADSHAW, A.D. Implications of genotypeenvironment interactionin applied plant breeding. Crop Science, Madison, v. 4, p. 503-508, 1964.

BALDISSERA, I.T., SCHERER, E.E. Correção da acidez do solo e adubação da cultura do feijão. In: EPAGRI. A cultura do feijão em Santa Catarina. Florianópolis: EPAGRI, 1992. cap. 6 , p. $115-136$.
BILBRO, J.D., RAY, L.L. Environment stability and adaptation of several cotton cultivars. Crop Science, Madison, v. 16, p. 821-824, 1966.

BISOGNIN, D.A., ALMEIDA, L.A., GUIDOLIN, A.F. et al. Desempenho de cultivares de feijão em semeadura tardia no Planalto Catarinense. Ciência Rural, Santa Maria, v. 27, n. 2, p. 193-199, 1997.

CRUZ, C.D., REGAZZI, A.J. Modelos biométricos aplicados ao

Ciência Rural, v. 29, n. 3, 1999. 
melhoramento genético, 2. ed. Viçosa: UFV, 1997. 390 p.

CRUZ, C.D. Aplicativo computacional em genética e estatística. Viçosa: UFV, 1997. 442 p.

EBERHART, S.A., RUSSEL, W.A. Stability parameters for comparing varieties. Crop Science, Madison, v. 6, p. 36-40, 1966.

GAMA. E.E.G., HALLAUER, A.R. Stability of hybrids produced from selected and unselected lines of maize. Crop Science, Madison, v. 20, p. 623-626, 1980.

GUIMARÃES, D.R. Plantas daninhas e seu controle na cultura do feijão. In: EPAGRI. A cultura do feijão em Santa Catarina. Florianópolis: EPAGRI, 1992. cap. 9, p. 171-176.

JOBIM, C.I.P. Utilização de variáveis ambientais na análise da interação genótipo $x$ ambiente em feijão (Phaseolus vulgaris L.). Porto Alegre. RS, 1990. 84 p. Tese (Mestrado em Fitotecnia)- Programa de Pós-graduação em Agronomia, Universidade Federal do Rio Grande do Sul, 1990.

RAMALHO, M.A.P., SANTOS, J.B., ZIMMERMANN, M, J de
O. Genética quantitativa em plantas autógamas: aplicações ao melhoramento do feijoeiro. Goiânia: UFG, 1993. 271p.

ROWE, P.R., ANDREW, R.H. Phenotypic stability for a systematic series of corn genotypes. Crop Science, Madison, v. 4 , p. $563-567,1964$

SMITH, R.R., BYTH, D.E., CALDWELL, B.E., et al. Phenotype stability in soybean populations. Crop Science, Madison, v. 7, p. 590-592, 1967.

SOARES, P.C., SEDIYAMA, C.S,, CRUZ, C.D. et al. Genotype $\mathrm{x}$ environment interaction and indirect selection of rice in irrigated and nonirrigated flood plain areas. Revista Brasileira de Genética, Ribeirão Preto, v. 18, n. 4, p. 563$569,1995$.

STEEL, R.G.D., TORRIE, J.L. Principles and procedures of statististics. New York: Mac Graw-Hill, 1960. 473 p.

WILDNER, L.P. Manejo do solo para cultura do feijão: Principais características e recomendações técnicas. In: EPAGRI. A cultura do feijão em Santa Catarina. Florianópolis: EPAGRI, 1992. cap. 5, p. 83-114.

Ciência Rural, v. 29, n. 3, 1999. 